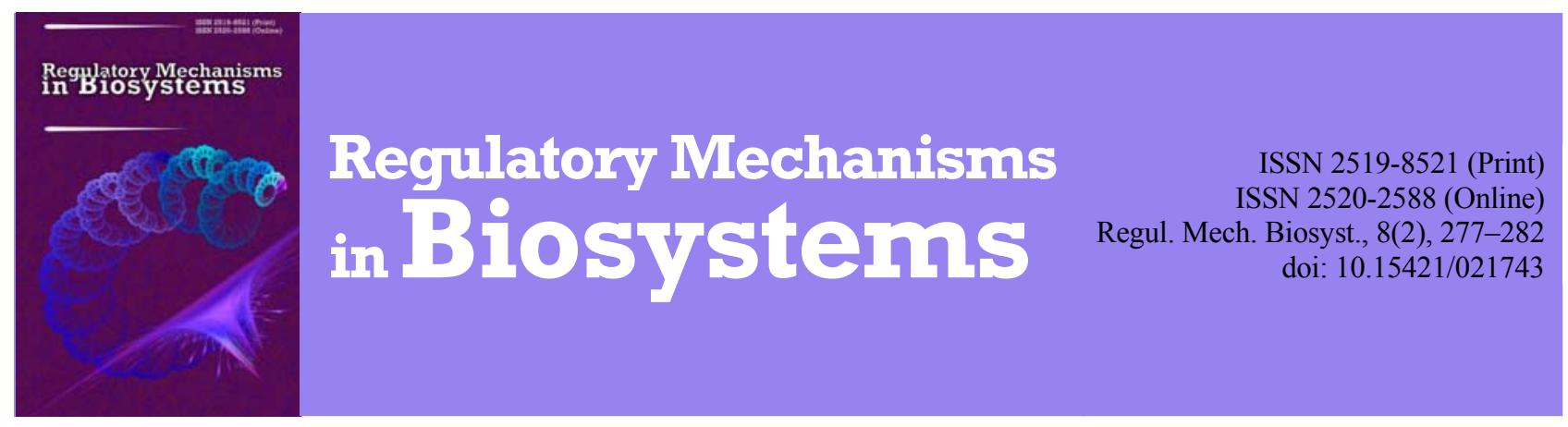

\title{
Optimization of postoperative analgesia after adenoidectomy in children
}

\author{
M. A. Georgiyants*, M. B. Pushkar*, O. V. Vysotska**, A. P. Porvan** \\ *Kharkiv Medical Academy of Postgraduate Education, Kharkiv, Ukraine \\ **Kharkiv National University of Radio Electronics, Kharkiv, Ukraine
}

Article info

Received 24.03.2017

Received in revised form 20.04.2017

Accepted 23.04.2017

Kharkiv Medical Academy of Postgraduate Education Department of Pediatric Anesthesiology and Intensive Therapy, Kultury Str., 11/83, Kharkiv, 61058, Ukraine Tel. +38-066-523-32-13 E-mail:eniram@bigmir.net
Georgiyants, M. A., Pushkar, M. B., Vysotska, O. V., \& Porvan, A. P. (2017). Optimization of postoperative analgesia after adenoidectomy in children. Regulatory Mechanisms in Biosystems, 8(2), 277-282. doi:10.15421/021743

It is known that pharyngalgia is very common after tonsillectomy. It should be emphasized that the intensity of pain after adenoidectomy in children is not less important than after adenotonsillectomy. Despite the availability of standardized pain assessment scales and existing postoperative analgesia recommendations, unresolved postoperative pain still occurs in children. The research included 117 children with an average age of $7.5 \pm 0.4$ years, who underwent adenoidectomy at the Department of Anesthesiology and Intensive Care of "Regional Children's Clinical Hospital" of Kharkov city in 2014. Depending on the method of general anesthesia, patients were divided into 3 groups: group I ( $n=41)$ those who received propofol in combination with fentanyl; group II $(n=40)$ those who received sevoflurane in combination with fentanyl; group III $(n=36)$ those who received thiopental sodium combined with fentanyl. We monitored the heart rate, systolic blood pressure, diastolic blood pressure, mean arterial pressure, BIS-index, heart rate variability, respiration rate, and $\mathrm{SpO}_{2}$. We determined the levels of cortisol and insulin in the blood serum, glucose level, the ratio of cortisol/insulin was calculated. Assessment of the efficiency of postoperative analgesia was performed using the Wong-Baker FACES Pain Scale («Faces») and the Oucher Scale. The result of analysis of the intensity of postoperative pain determined that at the 1st hour after the operation by the «Faces» and Oucher scales, it was significantly higher in patients of group II compared with the patients of group I and group III. The morning after the operation there was no significant difference in the pain scales, and the number of scale points showed that children from all groups did not have pain. According to the data of ANOVA it was determined that only the patients in group I with indicator $\triangle B I S$-index «intubation - traumatic moment of operation» experienced postoperative pain intensity on the «Faces» scale. A very strong correlation between «cortisol - BIS index» was observed during the traumatic moment of operation and unidirectional positive correlations were seen both between $\Delta B I S$-index «intubation-the traumatic moment of operation») and between the level of cortisolemia ( $\Delta$ cortisol before surgery - the traumatic moment of operation, $\Delta$ cortisol extubation - the 1 st day after the surgery and $\Delta$ cortisol before surgery - the 1 st day after the surgery) and the intensity of postoperative pain by the «Faces» and Oucher scales. The around-the-clock prescribed administration of ibuprofen at dose $10 \mathrm{mg} / \mathrm{kg}$ after adenoidectomy provided effective postoperative analgesia. At the $1 \mathrm{st}$ hour after the operation lower pain intensity was revealed in patients using propofol in combination with fentanyl by both pain scales. We believe that propofol is able to influence the level of cortisol and assume that due to minimal changes in the level of cortisol during the perioperative period, propofol can reduce the intensity of postoperative pain.

Keywords: removal of the adenoid vegetations, children, intravenous anaesthesia, inhalation anaesthesia, postoperative pain

\section{Introduction}

It is known that the greater the severity of surgical stress, the higher incidence of complications in the perioperative period. The most important aggressive factors of surgical stress are: psychoemotional aggression, pain, blood loss, nonpainful reflexes and damage to vital organs. In each case, the severity of the stress factors is quite different and depends on many factors. The leading factors are the initial state of vital body systems, traumatism of surgical intervention and the effectiveness of the techniques that the anaesthesiologist provides to protect the patient from nociceptive effects of surgical stress.

Speaking about surgical stress, it should be remembered that the basis of perioperative stress response is the reaction of the hypothalamic-pituitary-adrenal system, which causes hyperglycemia, an excessive production of adrenocorticotropic hormone (ACTH), cortisol, somatotropin, catecholamines, angiotensin II, glucagon, lactate formation and reduces the secretion of insulin, testosterone and activation of the sympathetic nervous system (Palmieri et al., 2006). Despite the fact that at the present time there is no direct method for measuring the stress level during general anesthesia, one of the most common criteria for evaluating stress is the level of stress hormones with hemodynamic parameters, which characterize the effectiveness of a patient's protection from surgical stress during surgery (Paola et al., 2015).

Today some of the most widely studied parameters in evaluating surgical stress in children and adults are cortisol and glucose (Wolf, 2012; Yang et al., 2013; Sekhon et al., 2013; Naguib et al., 2013; Gupta et al., 2013; Chen et al., 2013; Wang et al., 2014; Das et al., 2015). However, some of the existing attempts to evaluate stress reactions by studying the level of cortisol during diagnostic procedures and invasive urological interventions in children under general anesthesia have shown mixed results (Hsu et al., 2012; Taylor et al., 2013).

Thus, the main purpose of anesthesia is to protect the child from surgical stress. Stress has special significance in children with imperfections in their central and peripheral systems of neurohumoral regulation, which leads to low adaptability in such children's 
organism. That is why one of the main problems in ear, nose and throat (ENT)-surgery is to optimize the maintenance of perioperative analgesia (Strauss, 2012). However, recently the bulk of research on surgical stress in a variety of types of surgery (depending on the duration and extent of trauma) has been conducted on adult patients under different methods of general anesthesia compared to the pediatric patients. In addition, until now in the literature there has been a lack of data about the effectiveness of protecting children from surgical stress during "minimally invasive" operations, for example during adenoidectomy in children.

One of the most important factors which determine the postoperative period is pain in various degrees of severity (Tsekhmister et al., 2016). Acute pain is the most common adverse factor which affects children as a result of surgery, illness, injury or any necessary medical treatment. Adenotonsillectomy is associated with severe pain, which sometimes lasts until the seventh postoperative day (Uysal et al., 2011). However, in the literature, we have found only a few works about the intensity of postoperative pain after adenoidectomy in children.

This opinion is shared in the survey conducted by Russell et al. (2013), who noted that at present there is still a paucity of data which shows how painful the most common surgical procedures in children can be. Previous work has indicated that more than $80 \%$ of children need to receive analgesics after ambulatory adenoidectomy and discharge from the hospital (Kokki and Ahonen, 1997). Korpela et al. (2007) compared the efficacy of naproxen and acetaminophen with or without pethidine during adenoidectomy in children. They found that $83 \%$ of children of the naproxen group and $97 \%$ of the acetaminophen group who had not been given pethidine during surgery required the administration of additional analgesics in the ward (fentanyl $1 \mu \mathrm{g} / \mathrm{kg}$ ). Thus, the usage of pethidine reduced the need for additional analgesia in the postoperative period (Korpela et al., 2007). Therefore, the abovementioned work indicates that the intensity of pain in children after adenoidectomy is not less important than after adenotonsillectomy.

According to the results of a study conducted by Schnelle et al. (2013), which evaluated the intensity of postoperative pain in 134 children in the first 24 hours after ENT-operations using the German-wide project Quality Improvement in Postoperative Pain Management in Infants (QUIPSI) questionnaire, it was determined that the maximum intensity of pain in children is significant within the first 24 hours, and most children require additional analgesics. From the total number of surveyed patients, the majority of patients had undergone adenoidectomy $(60 \%)$ and combined with tonsillectomy $(16 \%)$. The authors concluded that the strategy of treating pain in children is not sufficient (Schnelle et al., 2013).

Vons et al. (2014) also evaluated the prevalence and severity of postoperative pain in 167 children, who underwent adenoidectomy (78 patients) and adenotonsillectomy (89 patients) in outpatient settings. The percentage of patients with significant pain, who were already at home on the 1st day after the surgery, according to the Parent's Postoperative Pain Measure Scale (over 6 points) and the visual analogue scale (over 4 points), was $25 \%$ and $35 \%$ respectively of the total number of patients who had undergone adenoidectomy (Vons et al., 2014). Probably, this may be due to the insufficient dose of non-narcotic analgesics in the postoperative period.

Based on the foregoing we believe that, despite the existing methods of general anesthesia which are designed to protect children from surgical stress, not enough attention has been devoted to the quality of antistress protection during «minimal» traumatic surgery and providing effective postoperative analgesia following ENT-operations in children. The aim of this research is to improve the experience of children during the postoperative period after adenoidectomy by reducing the intensity of postoperative pain.

\section{Materials and methods}

The research was conducted at the Department of Anesthesiology and Intensive Care "Regional Children's Clinical Hospital" (Kharkiv,
Ukraine) during 2014. It included 117 children with an average age of $7.5 \pm 0.4$ years, who underwent adenoidectomy and responded to ASA I-II. The average duration of surgery was $7.3 \pm 0.3 \mathrm{~min}$. All patients were divided into three groups depending on the method of general anesthesia.

Patients in group I $(n=41)$ underwent anesthesia using $1 \%$ solution of propofol $(2.5 \pm 0.03 \mathrm{mg} / \mathrm{kg})$, maintenance performed by bolus administration of propofol $(1 \mathrm{mg} / \mathrm{kg})$ for an average of $2.5-$ 3.0 minutes after previous administration.

Patients in group II $(n=40)$ underwent anesthesia using a sevoflurane-oxygen mixture given by the "bolus" method without filling the breathing circuit of $8 \%$ sevoflurane with oxygen flow $41 / \mathrm{min}$. Upon reaching the clinical- surgical stage of anesthesia, maintenance of anesthesia was performed at feed $2.0-2.5 \%$ sevoflurane in fresh gas flow of $21 / \mathrm{min}$.

Patients in group III $(n=36)$ underwent anesthesia using a $1 \%$ solution of thiopental sodium $(5-6 \mathrm{mg} / \mathrm{kg})$. Given the short duration of the intervention, there was no need for repeated administration of anesthetic to maintain the anesthesia.

In all groups, muscle relaxation was ensured by administering a $2 \%$ solution of suxametonium iodide at a dose $(2 \mathrm{mg} / \mathrm{kg})$. As needed, further bolus administration of suxametonium iodide was performed at average dose $(1 \mathrm{mg} / \mathrm{kg})$. Intraoperative analgesia was carried out by $0.005 \%$ solution of fentanyl at a dose $(2 \mathrm{mg} / \mathrm{kg})$.

In order to prevent nausea and vomiting in patients of all groups, ondansetron was administered $(0.1 \mathrm{mg} / \mathrm{kg})$ intraoperatively. Postoperative analgesia in all groups was performed by around-theclock prescribed ibuprofen at a dose $(10 \mathrm{mg} / \mathrm{kg})$.

Perioperative non-invasive monitoring of the heart rate, ECG, systolic, diastolic and mean arterial pressure (MAP), heart rate variability (HRV), respiration rate, blood oxygen saturation index (SpO2) was carried out by the UM-300 monitor (Utas, Ukraine) at the following stages: 1st is before surgery; 2nd is induction of anesthesia; 3rd is tracheal intubation; 4th is traumatic moment of operation; 5th is extubation; 6th is 1st hour after the surgery; 7th is 6th hour after the surgery; 8 th is 1st postoperative day.

The HRV parameters were examined at all stages, except for the 3rd stage (tracheal intubation). BIS-index was investigated by the UM-300 monitor (Utas, Ukraine) and BIS Vista (Aspect Medical Systems, USA). The data at the 1st, 3rd, 4th and 5th stages were evaluated. Doses were titrated to maintain BIS-index in the range of $40-60 \%$.

The level of cortisol (C) in serum was determined by ELISA using a set of reagents of production (XEMA-MEDICA, Russia). Insulin levels (I) were determined by a set of reagents of production (DRG, Germany). Glucose was determined by the glucose oxidase method using a set of reagents of production (Filisit-Diagnostics, Ukraine). They were evaluated in the following stages: 1st, 4th, 5th and 8th.

Evaluating the effectiveness of pain relief in the early postoperative period was performed by using the Wong-Baker FACES Pain Scale «Faces» and the Oucher scale at the following stages: at the 1st, 6th, 8th hour and on the 1st day after the operation.

Statistical analysis of the data was performed using SPSS 19 for Windows. Results of descriptive statistics are presented as Mean \pm $\mathrm{SE}$ (mean \pm standard error of mean). Check for normal distribution was carried out by the Kolmogorov-Smirnov criterion. We used tStudent test to compare quantitative indicators and determine the differences between them for dependent and independent samples with Bonferroni correction. Correlation analysis was carried out using the criterion of Pearson (r). An ANOVA was carried out with the calculation of Fisher's F-test in order to assess the effect of the studied factors on the pain intensity.

\section{Results}

Patients of all groups were matched by sex, age, anthropometric data and the duration of surgery. Hemodynamic parameters in 
patients of all groups did not differ and were stable during surgery. BIS-index had the same tendency to change in patients of all groups $(40 \%<$ BIS-index $<60 \%$ ), but in the stages of study some differences were found between patients of groups I and III and patients of groups II and III ( $\mathrm{P}=0.002$ and $\mathrm{P}=0.014$, respectively), which were not clinically significant (Table 1).

\section{Table 1}

The changes of the hypnotic component of general anaesthesia (BIS-index) in patients of all groups in the perioperative period (Mean $\pm \mathrm{SE}$ )

\begin{tabular}{lcccc}
\hline \multirow{2}{*}{ Groups } & \multicolumn{4}{c}{ Stages of study } \\
\cline { 2 - 5 } & 1st & 3rd & 4th & 5th \\
\hline group I, $\mathrm{n}=41$ & $95.8 \pm 0.5^{* *}$ & $52.2 \pm 1.7$ & $51.5 \pm 1.6^{*}$ & $76.5 \pm 0.9$ \\
group II, $\mathrm{n}=40$ & $96.6 \pm 0.3^{*}$ & $42.1 \pm 1.1^{* * *}$;\# & $46.4 \pm 2.6^{* * *}$ & $78.5 \pm 0.6$ \\
group III, $\mathrm{n}=36$ & $97.5 \pm 0.2$ & $54.8 \pm 1.0$ & $56.0 \pm 1.2$ & $78.3 \pm 0.6$ \\
\hline
\end{tabular}

Note: significant difference between the groups at appropriate stages: \#\#- $\mathrm{P}<0.001$ compared with group $1 ;{ }^{*}-\mathrm{P}<0.05$ compared with group 3, $* *-\mathrm{P}<0.01$ compared with group $3, * * *-\mathrm{P}<0.001$ compared with group 3 .

In assessing the effectiveness of the antistress protection of children during surgery we found that the largest fluctuations were inherent in the level of cortisol among stress markers. During the traumatic moment of operation in the patients of group I and during all stages of the study, the level of cortisol did not exceed the limits of the reference values. However, the patients of groups II and III had a more significant tendency to increase its level. But it should be noted, that there was no significant difference between the groups at this stage $(\mathrm{P}>0.05)($ Table $2-5)$.

Table 2

Comparative dynamics of cortisol (nmol/l) in the studied groups throughout different research stages (Mean \pm SE)

\begin{tabular}{ccccc}
\hline \multirow{2}{*}{$\begin{array}{c}\text { Stages } \\
\text { of study }\end{array}$} & $\begin{array}{c}\text { group 1, } \\
\mathrm{n}=21\end{array}$ & $\begin{array}{c}\text { group 2, } \\
\mathrm{n}=19\end{array}$ & $\begin{array}{c}\text { group 3, } \\
\mathrm{n}=20\end{array}$ & $\begin{array}{c}\text { Reference } \\
\text { values }\end{array}$ \\
\hline 1st & $260.0 \pm 24.4$ & $322.0 \pm 88.3$ & $308.1 \pm 44.5$ & \\
4th & $333.3 \pm 37.2$ & $830.0 \pm 322.3$ & $506.3 \pm 218.2$ & $370 \pm 230$ \\
5th & $413.3 \pm 44.3^{\text {\#\# }}$ & $606.7 \pm 48.1^{* * *} ;$ & $322.5 \pm 62.4$ & \\
8th & $310.0 \pm 75.3$ & $304.0 \pm 61.4$ & $207.6 \pm 38.1$ & \\
\hline
\end{tabular}

Note: significant difference between cortisol values at different stages: ${ }^{* * *}-\mathrm{P}<$ 0.001 compared with 8th stage; significant difference between the groups: ${ }^{\#}-\mathrm{P}<$ 0.01 compared with group $2,{ }^{\ldots}-\mathrm{P}<0.001$ compared with group 3 .

Table 3

Comparative dynamics of insulin ( $\mu$ unit/ml) in the studied groups throughout different research stages (Mean $\pm \mathrm{SE}$ )

\begin{tabular}{ccccc}
\hline $\begin{array}{c}\text { Stages } \\
\text { of study }\end{array}$ & group 1, $\mathrm{n}=21$ & Group 2, $\mathrm{n}=19$ & group 3, $\mathrm{n}=20$ & $\begin{array}{c}\text { Reference } \\
\text { values }\end{array}$ \\
\hline 1 th & $11.8 \pm 1.0$ & $7.2 \pm 0.6$ & $12.0 \pm 1.9$ & \\
4 th & $14.7 \pm 2.3$ & $12.9 \pm 6.4$ & $15.0 \pm 2.0$ & $13.5 \pm$ \\
5 th & $12.5 \pm 1.9$ & $12.9 \pm 1.9$ & $14.3 \pm 2.2$ & 11.5 \\
8 th & $10.0 \pm 2.1$ & $16.5 \pm 1.9^{* * * * \#}$ & $11.2 \pm 0.6$ & \\
\hline
\end{tabular}

Note: significant difference between insulin values at different stages: ${ }^{* * *}$ $\mathrm{P}<0.001$ compared with 1st stage; significant difference between the groups: ${ }^{\text {- }}$ $\mathrm{P}<0.01$ compared with group $3,{ }^{\prime}-\mathrm{P}<0.001$ compared with group 2 .

\section{Table 4}

Comparative dynamics of ratio cortisol / insulin (C/I) in the studied groups throughout different research stages $($ Mean $\pm \mathrm{SE}$ )

\begin{tabular}{ccccc}
\hline \multirow{2}{*}{$\begin{array}{c}\text { Stages } \\
\text { of study }\end{array}$} & group 1, n=21 & group 2, $\mathrm{n}=19$ & group 3, $\mathrm{n}=20$ & $\begin{array}{c}\text { Reference } \\
\text { values }\end{array}$ \\
\hline 1 st & $1.0 \pm 0.1$ & $1.0 \pm 0.1^{* *}$ & $1.0 \pm 0.1$ & \\
4 th & $1.2 \pm 0.2$ & $2.3 \pm 0.6$ & $1.1 \pm 0.3$ & $1.0 \pm 0.1$ \\
5 th & $1.2 \pm 0.4$ & $2.0 \pm 0.5^{* *}$ & $1.4 \pm 0.5$ & \\
8 th & $1.1 \pm 0.2$ & $0.5 \pm 0.1^{\text {\#\# }}$ & $0.8 \pm 0.3$ & \\
\hline
\end{tabular}

Note: significant difference between $\mathrm{C} / \mathrm{I}$ values at different stages: ${ }^{* *}-\mathrm{P}<$ 0.01 compared with 8 th stage; significant difference between the groups: \#- $\mathrm{P}<0.01$ compared with group 1 .

At all stages of the study, the level of insulin did not exceed the limits of reference values in the patients of all groups. Among all studied groups only in the patients of group II was there a tendency to increase the ratio of $\mathrm{C} / \mathrm{I}$ up to $2.3 \pm 0.6$ at the stage of the traumatic moment of operation, which indicates the intensity of adaptation abilities of patients in this group. The level of glycemia in patients of all groups did not exceed the limits of reference values $(4.4 \pm 1.1 \mathrm{mmol} / \mathrm{l})$ during all stages of the study.

Based on this, a correlation analysis was made between stress markers, hemodynamic parameters and the BIS-index.

Table 5

Comparative dynamics of glucose $(\mathrm{mmol} / \mathrm{l})$ in the studied groups throughout different research stages (Mean $\pm \mathrm{SE})$

\begin{tabular}{ccccc}
\hline $\begin{array}{c}\text { Stages } \\
\text { of study }\end{array}$ & group 1, $\mathrm{n}=21$ & Groups $2, \mathrm{n}=19$ & $\begin{array}{c}\text { Reference } \\
\text { values }\end{array}$ \\
\hline 1 st & $3.5 \pm 0.1$ & $3.3 \pm 0.5$ & $3.7 \pm 0.2$ & \\
4 th & $3.9 \pm 0.2^{* *}$ & $3.4 \pm 0.4$ & $3.6 \pm 0.2$ & $4.4 \pm 1.1$ \\
5 th & $4.5 \pm 0.1$ & $4.6 \pm 0.4$ & $4.2 \pm 0.3$ & \\
8 th & $3.8 \pm 0.3$ & $3.9 \pm 0.3$ & $4.3 \pm 0.1^{++}$ & \\
\hline
\end{tabular}

Note: significant difference between glucose values at different stages: ${ }^{+}$ $\mathrm{P}<0.01$ compared with 1 st stage, ${ }^{* *}-\mathrm{P}<0.01$ compared with 5 th stage.

In the patients of group I at the stage of the traumatic moment of operation we noted strong negative "insulin - heart rate" $(\mathrm{r}=-0.81$; $\mathrm{P}=0.05)$; strong positive " $\mathrm{C} / \mathrm{I}$ - heart rate" $(\mathrm{r}=0.81 ; \mathrm{P}=0.05)$ and a very strong positive "cortisol - BIS-index" $(\mathrm{r}=0.97 ; \mathrm{P}=0.001)$ correlations. On the 1st postoperative day we noted a strong connection "cortisol - heart rate" $(\mathrm{r}=0.83, \mathrm{P}=0,041)$.

In the patients of group II within all stages of the study at the stage of extubation we established only one strong positive correlation "glucose - BIS index" $(\mathrm{r}=0.75, \mathrm{P}=0.011)$.

In the patients of group III at the preoperative stage we noted moderate positive connection "glucose - MAP" $(\mathrm{r}=0.44, \mathrm{P}=$ 0.048). At the traumatic moment of operation strong correlation links were recorded: "glucose - BIS-index" $(\mathrm{r}=0.72, \mathrm{P}=0.004)$ and "insulin - BIS-index" $(\mathrm{r}=-0.85 ; \mathrm{P}=0.031)$. On the $1 \mathrm{st}$ postoperative day there was a noticeable positive correlation "glucose - heart rate" $(\mathrm{r}=0.51, \mathrm{P}=0.02)$.

When examining the pain intensity using the "Faces" scale in the early postoperative period there was more pronounced pain in the patients of group II ( $1.4 \pm 0.2$ points) in comparison with the patients of the group I $(0.8 \pm 0.1$ points $)$ and group III $(0.8 \pm 0.1$ points) $(\mathrm{P}=0.013$ and $\mathrm{P}=0.014$, respectively) (Fig. 1).

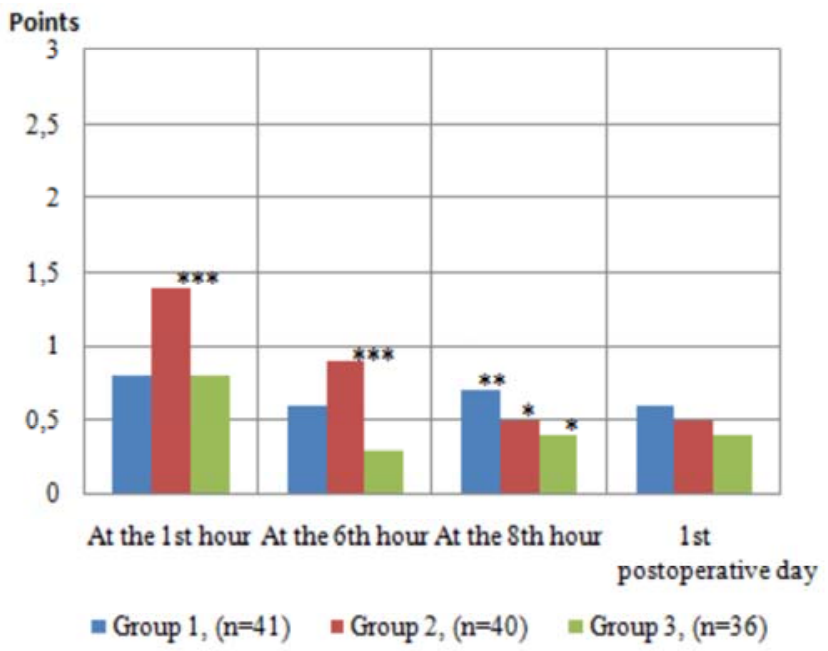

Fig. 1. Dynamics of "Faces" scale indicators in the postoperative period in patients of all groups

By the Oucher scale a similar pattern was traced, but at the same time apart from the above differences we detected the difference between the patients of groups I and III $(\mathrm{P}=0.011)$ (Fig. 2).

At the 6th hour after the operation the intensity of postoperative pain on the "Faces" scale was significantly lower in the patients of group III $(0.3 \pm 0.1$ points $)$ compared with the patients of group I $(0.6 \pm 0.1$ points $)$ and group II $(0.9 \pm 0.2$ points $)(\mathrm{P}=0.013$ and $\mathrm{P}=$ 
0.001 , respectively) and by the Oucher scale - the same in the patients of group III $(0,3 \pm 0,1$ points $)$ compared only with the patients of group II $(0.6 \pm 0.1$ points $)(\mathrm{P}=0.014)$.

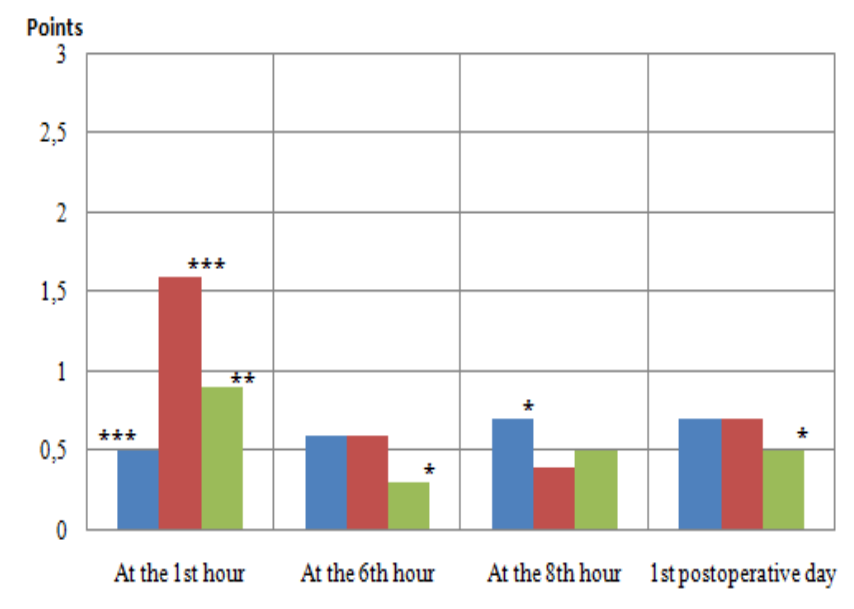

- Group 1, (n=41) - Group 2, (n=40) ॥ Group 3, (n=36)

Fig. 2. Dynamics of Oucher scale indicators in the postoperative period in patients of all groups

In the dynamics of observation in the patients of all groups a tendency was noted to increase of pain intensity in the postoperative period, but only in the patients of group I did we not observe significant differences of the pain intensity between the stages of the study $(\mathrm{P}>0.05)$. The next morning after the operation the number of scale points showed that postoperative pain did not trouble children of all groups $(\mathrm{P}>0.05)$.

Given the very strong positive correlation "cortisol - BISindex" $(r=0.97, P=0.001)$ in the patients of group I at the stage of the traumatic moment of the operation, we carried out a more detailed analysis of the relationships between the level of stress markers, hemodynamic parameters, BIS-index and the differences of these parameters between the stages of the study, which have been marked $(\Delta)$. We noted, that patients for whom the value of $\Delta$ BIS-index "intubation - traumatic moment of operation" ( $\Delta \mathrm{BIS})$ was negative did not experience postoperative pain according to the "Faces" and Oucher scales starting from the 6th hour after the operation until the 1st postoperative day inclusive.

Following the analysis of variance, it was found that only in the patients of group I did $\Delta B I S$ affect the intensity of postoperative pain according to the "Faces" scale at the following stages: at the 6th hour after the operation $(\mathrm{F}=4.278 ; \mathrm{P}=0.039)$, at the 8 th hour after the operation $(\mathrm{F}=4.583, \mathrm{P}=0.032)$ and on the $1 \mathrm{st}$ postoperative day $(\mathrm{F}=4.583, \mathrm{P}=0.032)$. Patients of groups II and III felt no effect of $\triangle \mathrm{BIS}$ on the intensity of postoperative pain during all stages of the study $(\mathrm{P}>0.05)$. In addition, it should be noted that the value of $\Delta \mathrm{BIS}$ in the patients of groups II and III $(4.54 \pm 1.45 \%$ and $3.76 \pm 0.66 \%$, respectively) was significantly higher in comparison with the patients of group I $(-0.73 \pm 1.03 \%)$ $(\mathrm{P}=0.007$ and $\mathrm{P}=0.002$, respectively).

The results of studying the effect of the level of stress markers in the perioperative period on the intensity of postoperative pain in the patients of all groups showed: first, only changes in the level of cortisol influenced the intensity of postoperative pain according to pain scales; secondly, it was registered only in the patients of group I.

In particular, the value of $\Delta$ cortisol at the stage "before surgery the traumatic moment of operation" affected the pain intensity: on the "Faces" scale on the 1st day after the operation $(\mathrm{F}=4.321 ; \mathrm{P}=$ 0.038 ), according to the Oucher scale at the 6th hour after the operation and on the 1st day after the operation $(\mathrm{F}=3.900 ; \mathrm{P}=$ 0.048 and $\mathrm{F}=5.417 ; \mathrm{P}=0.020$, respectively). Also it was found that $\Delta$ cortisol at the stage "extubation - the 1st day after the surgery" affected the pain intensity on the "Faces" scale at the 1st hour after the operation $(\mathrm{F}=4.792 ; \mathrm{P}=0.029)$ and on the Oucher scale at the 1st hour after the operation $(\mathrm{F}=4.309 ; \mathrm{P}=0.038)$; the value of $\Delta$ cortisol at the stage "before surgery - the 1st day after the surgery" affected the pain at the 1st hour after the operation according to the "Faces" scale $(\mathrm{F}=4.684 ; \mathrm{P}=0.030)$. Regarding the patients of groups II and III, we did not register the influence of $\Delta$ cortisol on the intensity of postoperative pain during any of the stages of the study (before surgery - the traumatic moment of operation; the traumatic moment of operation - extubation; extubation - the 1st day after the surgery) $(\mathrm{P}>0.05)$.

However attention should be drawn to the following: in the patients of group II, the value of $\Delta$ cortisol "before surgery - the traumatic moment of operation" was significantly higher (582.5 \pm $203.7 \mathrm{nmol} / \mathrm{l})$ compared with the patients of group I $(46.0 \pm 12.6$ $\mathrm{nmol} / \mathrm{l})(\mathrm{P}=0.010)$ and group III $(122.7 \pm 144.8 \mathrm{nmol} / \mathrm{l})(\mathrm{P}=$ 0.013 ), which is likely to contribute to the development of more severe postoperative pain in the patients of group II. Moreover, the intensity of postoperative pain in the patients operated on under general anesthesia using sevoflurane in combination with fentanyl, was higher compared with the patients of groups I and III according to the pain scales.

Based on the results of the correlation analysis it was established that a noticeable positive correlation was marked: between the $\Delta \mathrm{BIS}-$ index "intubation - the traumatic moment of operation" and the "Faces" scale at the 6th hour after the operation $(\mathrm{r}=0.65, \mathrm{P}=0.029)$; between the $\Delta \mathrm{BIS}$-index "intubation - the traumatic moment of operation" and the "Faces" scale at the 8th hour after the operation $(\mathrm{r}=$ $0.67 ; \mathrm{P}=0.022)$ and between the $\Delta \mathrm{BIS}$-index "intubation - traumatic moment of operation" and the "Faces" scale on the 1st day after the operation $(\mathrm{r}=0.70, \mathrm{P}=0.019)$.

In the study of the correlation between $\Delta$ cortisol and pain intensity by pain scales, significant positive correlation was observed on the 1st day after the operation in the patients of group I: $\Delta$ cortisol (before surgery - the traumatic moment of operation) the "Faces" scale $(\mathrm{r}=0.58 ; \mathrm{P}=0.031)$; $\Delta$ cortisol (before surgery the traumatic moment of the operation) - the Oucher Scale $(\mathrm{r}=$ $0.64 ; \mathrm{P}=0.013$ ). Also, noticeable positive correlation relationships were found at the 1 st hour after the operation: $\Delta$ cortisol (extubation - the 1st day after surgery) the "Faces" scale $(r=0.57$, $\mathrm{P}=0.031), \Delta$ cortisol (extubation - the 1st day after surgery) the Oucher scale $(\mathrm{r}=0.52, \mathrm{P}=0.04)$. In addition, at the 1st hour after the operation we found a noticeable positive correlation between $\Delta$ cortisol (before surgery - the 1st day after the operation) - pain on the "Faces" scale $(\mathrm{r}=0.58, \mathrm{P}=0.031)$.

\section{Discussion}

The evaluation of the efficiency of antistress protection during adenoidectomy in children found that the most sensitive indicator of surgical stress among all studied stress markers was the level of cortisol. In summary, during all stages of the research, the cortisol level did not differ between the groups. However, at first, only in the patients of group I its level did not go beyond reference values for all stages of the research and secondly, in the patients of groups II and III a significant upward trend in cortisol was noted during the traumatic moment of operation, but there were no significant differences between groups at this stage $(\mathrm{P}>0.05)$.

First of all, it is necessary to note that cortisol secretion is increased as a result of stimulation of the adrenal cortex by means of ACTH. An increase in the concentration of ACTH and cortisol in plasma can be detected almost immediately after the onset of surgery and their increase is related to the intensity of the surgical stimulus (Paola et al., 2015). But despite this, there are current studies which show that propofol can reduce the secretion of cortisol by inhibiting $\gamma$-aminobutyric acid and glutamate receptors (Sakai et al., 1995; Kelbel and Weiss, 2001).

Apparently, that is why the results obtained on the effectiveness of the antistress protection of general anesthesia with the use of propofol and sevoflurane are confirmed in some existing works. Chen et al. (2013) in his study determined which of the methods of 
general anesthesia has more advantages during fibrobronchoscopy in children. According to the study, they found that anesthesia with propofol in combination with remifentanil has more advantages in comparison with sevoflurane, one of which is a significantly lower stress hormone level during surgery.

In another study (Yusupov et al., 2015), based on analysis of 64 patients who underwent surgery for the correction of congenital malformations also came to the conclusion that general anesthesia with propofol and analgesia nalbuphine provides sufficient protection of children from surgical stress without signs of activation of hormonal regulation. It should also be noted that the present works which investigate the level of stress markers in adult patients when intravenous and inhalation anesthesia are compared also demonstrate the advantages of propofol in combination with remifentanil in relation to sevoflurane (Ihn et al., 2009; Marana et al., 2010).

By the way, if we recall the depth of the hypnotic component of general anesthesia, we also found work in the current literature that discusses of the depth of the hypnotic component caused by propofol on surgical stress. Yang et al. (2013) compared the effect of varying depths of the hypnotic component of anesthesia using propofol in combination with remifentanil on perioperative changes in hemodynamics and stress hormones during adenotonsillectomy in children. According to the results of the study, they concluded that a deeper level of sleep (BIS-index - 25-35\%) can more effectively inhibit perioperative cortisol reaction.

Jung and Cho (2015) compared the reaction of stress markers (norepinephrine and glucose) at different depths of sleep in patients operated on for the lung resection. The authors also concluded that a deeper level of anesthesia, which is achieved by the high rate infusion of propofol during surgery, provides a low perioperative response of the above indices.

During the course of our research, we did not study the effect of the depth of the hypnotic component of anesthesia on surgical stress. However, the data obtained from the level of stress markers confirm the fact that despite a shallow level of sleep (BIS-index $51.9 \pm 1.9 \%$ ) in patients of the group I, compared to previous studies (BIS-index - 25-35\%), they were sufficiently protected from the effects of surgical stress. The revealed strong positive correlation "cortisol - BIS-index" ( $\mathrm{r}=0.97, \mathrm{P}=0.001)$ in the patients of this group, in our opinion, is the evidence of the influence of the depth of sleep, caused by propofol, on the level of cortisol, and hence the severity of surgical stress.

Regarding the patients of groups II and III and the tendency to increase in cortisol level at the stage of the traumatic moment of operation, in view of the lack of understanding of the current range of increase in the cortisol level in response to various types of stress, including surgical, we believe that this fact requires further studies.

Returning to postoperative analgesia, despite the availability of standardized pain assessment scores and existing reviews and recommendations on the efficiency of analgesics, postoperative pain is still found in children (Messerer et al., 2010; Pierce and Voss, 2010; Russell et al., 2013; Schultz-Machata et al., 2014; Misiołek et al., 2014).

The analysis of postoperative analgesia in the work Schnelle et al. (2013) pointed out that only about $32 \%$ of the total number of children received ibuprofen in an average dose $8.39 \pm 1.62 \mathrm{mg} / \mathrm{kg}$, while $38 \%$ did not receive non-narcotic analgesics in the postoperative period. Maximum pain intensity over the first 24 hours in children was significant, prompting the authors to conclude that a higher percentage of children need more analgesics. The obtained results can be interpreted in different ways, as they can also be the consequence of the administration of analgesics according to the child's specific needs, but not according to their planned use. Therefore, we assume that a child's refusal to accept analgesia cannot for certain be considered as an indicator of adequate analgesia (or absence of pain), because there may also exist the factor of the neglect of postoperative analgesia by the child or its parents. During our study, around-the-clock prescribed administration of ibuprofen to all patients at the maximum single dose of $10 \mathrm{mg} / \mathrm{kg}$, in our opinion, provided more effective postoperative analgesia in comparison with the above results, which was demonstrated by using the pain scales.

Frederick et al. (2011) in their work examined 40 children aged 2-8 years and studied the effect of controlled sleep depth under anesthesia using sevoflurane on the emergence delirium by distributing patients into two groups: a "low normal" range (40$45 \%$ ) and a "high normal" range (55-60\%) by means of the BIS index during ophthalmic operations. They found, that in the patients of the group (BIS-index - 40-45\%) the score on the behavioral pain scale FLACC was significantly higher -7 points compared with the other group (BIS-index $-55-60 \%)-3.5$ points $(\mathrm{P}=0.03)$, despite the same amount of intraoperatively administered fentanyl in both groups (Frederick et al., 2011). During our study, we also recorded similar data, in particular, in children who were operated on under general anesthesia using sevoflurane, the BIS-index at the tracheal intubation stage was significantly lower $(42.1 \pm 1.1 \%)$ compared with children who were operated on under intravenous general anesthesia with propofol and thiopental sodium $(52.2 \pm 1.7 \%$ and $54.8 \pm 1.0 \%$, respectively; $\mathrm{P}=0.001)$. Later during the traumatic moment of operation for children of the sevoflurane group a tendency remained towards lower values in the hypnotic component of general anesthesia relative to the other two groups $(46.4 \pm 2.6 \%, 51.5 \pm 1.6 \%$ and $56,0 \pm 1.2 \%$, respectively). In the 1 st hour after the operation, the pain intensity in children who were operated on under general anesthesia using sevoflurane was higher on the "Faces' and Oucher scales $(1.4 \pm 0.2$ and $1.6 \pm 0.3$ points, respectively) compared with children who were operated on under intravenous general anesthesia with propofol and thiopental sodium $(0.8 \pm 0.1,0.5 \pm 0.1,0.8 \pm 0.1$ and $0.9 \pm 0.2$ points, respectively) Therefore, we also share the opinion of Frederick et al. (2011), that further research is needed to investigate the effect of the depth of the hypnotic component of anesthesia, caused by various methods of general anesthesia, on the intensity of postoperative pain.

Currently, the question of the influence of propofol on the intensity of postoperative pain is being discussed, in particular it is stated that it provides a more powerful analgesic effect in the postoperative period in comparison with other anesthetics (Hasani et al., 2013; Tan et al., 2010). However, none of the authors explain why this is happening. Our data also showed that in the 1st hour after adenoidectomy in children operated on under general anesthesia using propofol in combination with fentanyl, the pain intensity was the lowest, assessed by the "Faces" and Oucher scales, compared with two other methods of general anesthesia. We assume that this may be related to the ability of propofol to reduce the secretion of cortisol. The strong positive correlation "cortisol - BIS-index" $(\mathrm{r}=0.97 ; \mathrm{P}=0.001)$ in patients of group I is direct evidence of the influence of the depth of the hypnotic component of anesthesia caused by propofol on the level of cortisol. As a result, the level of cortisol changed minimally during all stages of the study in patients operated on under general anesthesia using propofol in combination with fentanyl.

It is known that if the level of some hormones increases above reference values (cortisol, progesterone, estrogen, testosterone and thyroid hormones), it will be impossible to provide adequate pain relief (Mensah-Nyagan et al., 2009).

The results of our study revealed the unidirectional positive correlation between $\triangle \mathrm{BIS}$ and postoperative pain intensity, and between the level of cortisol ( $\Delta$ cortisol before surgery - the traumatic moment of operation, $\Delta$ cortisol extubation - the 1 st day after surgery and $\Delta$ cortisol before surgery - the 1st day after surgery) and postoperative pain intensity. The obtained results, in our opinion, to some extent explain the relationship between the level of cortisol and postoperative pain. Given this, we assume, that it is due to the relative balance of cortisol level (remaining within the reference values $-140-600 \mathrm{nmol} / \mathrm{l}$ ) in the perioperative period in patients operated on under general anesthesia using propofol in combination with fentanyl, that we were able to provide more adequate pain relief and less pain intensity in the early postoperative period, compared with the patients from two other groups. However, 
our hypothesis requires further research. In the case of its confirmation, given the direct impact of the depth of the hypnotic component of general anesthesia based on propofol on the secretion of cortisol, further studies are needed to determine which optimal range of BIS-index anesthesiologists must use during operations in order to not only avoid an excessively deep or too superficial hypnotic component of general anesthesia, but also to predict the likely quality of postoperative analgesia. It is worth noting the fact that patients operated on under general anesthesia using propofol in combination with fentanyl, in which the value of $\Delta B I S$ "intubation - the traumatic moment of operation" was negative, did not experience postoperative pain on the "Faces" and Oucher scales, starting from the 6th hour after the operation until the 1st postoperative day inclusive.

\section{Conclusion}

A lower pain intensity, assessed by the "Faces" and Oucher scales, was observed at the 1st hour after the operation in patients using propofol in combination with fentanyl compared with the patients who received general anesthesia with sevoflurane or thiopental sodium in combination with fentanyl ( $\mathrm{P}=0.013$ and $\mathrm{P}=0.011$, respectively).

The around-the-clock administration of ibuprofen at a dose $10 \mathrm{mg} / \mathrm{kg}$ after adenoidectomy provides effective postoperative analgesia in children of all groups and there is no need for additional prescription of analgesics during their entire stay in hospital.

\section{References}

Chen, L., Yu, L., Fan, Y., \& Manyande, A. (2013). A comparison between total intravenous anaesthesia using propofol plus remifentanil and volatile induction/maintenance of anaesthesia using sevoflurane in children undergoing flexible fibreoptic bronchoscopy. Anaesthesia and Intensive Care, 41(6), 742-749.

Das, W., Bhattacharya, S., Ghosh, S., Saha, S., Mallik, S., \& Pal, S. (2015). Comparison between general anesthesia and spinal anesthesia in attenuation of stress response in laparoscopic cholecystectomy: A randomized prospective trial. Saudi Journal of Anaesthesia, 9(2), 184-188.

Frederick, H. J., Wofford, K. A., deL Dear, G., Funk, E., Weldon, B. C., \& Schulman, S. R. (2011). A randomized controlled trial in children having ophthalmic surgery to determine the effect of depth of anesthesia on emergence agitation. American Society of Anesthesiologists (ASA) Annual Meeting (Chicago, Illinois, October 15-19, 2011), A043.

Gupta, K., Maggo, A., Jain, M., Gupta, P. K., Rastogi, B., \& Singhal, A. B. (2013). Blood glucose estimation as an indirect assessment of modulation of neuroendocrine stress response by dexmedetomidine versus fentanyl premedication during laparoscopic cholecystectomy: A clinical study. Anesthesia, Essays and Researches, 7(1), 34-38.

Hasani, A., Gecaj-Gashi, A., Llullaku, S., \& Jashari, H. (2013). Postoperative analgesia in children after propofol versus sevoflurane anesthesia. Pain Medicine, 14(3), 442-446.

Hsu, A. A., von Elten, K., Chan, D., Flynn, T., Walker, K., Barnhill, J., Naun, C., Pedersen, A. M., Ponaman, M., Fredericks, G. J., Crudo, D. F., \& Pinsker, J. E. (2012). Characterization of the cortisol stress response to sedation and anesthesia in children. The Journal of Clinical Endocrinology and Metabolism, 97(10), 1830-1835.

Ihn, C. H., Joo, J. D., Choi, J. W., Kim, D. W., Jeon, Y. S., Kim, Y. S., Jung, H. S., \& Kwon, S. Y. (2009). Comparison of stress hormone response, interleukin6 and anaesthetic characteristics of two anaesthetic techniques: Volatile induction and maintenance of anaesthesia using sevoflurane versus total intravenous anaesthesia using propofol and remifentanil. Journal of International Medical Research, 37(6), 1760-1771.

Jung, S. M., \& Cho, C. K. (2015). The effects of deep and light propofol anesthesia on stress response in patients undergoing open lung surgery: A randomized controlled trial. Korean Journal of Anesthesiology, 68(3), 224-231.

Kelbel, I., \& Weiss, M. (2001). Anaesthetics and immune function. Current Opinion in Anaesthesiology, 14(6), 685-691.

Kokki, H., \& Ahonen, R. (1997). Pain and activity disturbance after paediatric day case adenoidectomy. Paediatric Anaesthesia, 7(3), 227-231.

Korpela, R., Silvola, J., Laakso, E., \& Meretoja, O. A. (2007). Oral naproxen but not oral paracetamol reduces the need for rescue analgesic after adenoidectomy in children. Acta Anaesthesiologica Scandinavica, 51(6), 726-730.
Marana, E., Colicci, S., Meo, F., Marana, R., \& Proietti, R. (2010). Neuroendocrine stress response in gynecological laparoscopy: TIVA with propofol versus sevoflurane anesthesia. Journal of Clinical Anesthesia, 22(4), 250-255.

Mensah-Nyagan, A. G., Meyer, L., Schaeffer, V., Kibaly, C., \& PatteMensah, C. (2009). Evidence for a key role of steroids in the modulation of pain. Psychoneuroendocrinology, 34(Suppl. 1), 169-177.

Messerer, B., Gutmann, A., Weinberg, A., \& Sandner-Kiesling, A. (2010). Implementation of a standardized pain management in a pediatric surgery unit. Pediatric Surgery International, 26(9), 879-889.

Misiołek, H., Cettler, M., Woroń, J., Wordliczek, J., Dobrogowski, J., \& Mayzner-Zawadzka, E. (2014). The 2014 guidelines for post-operative pain management. Anaesthesiology Intensive Therapy, 46(4), 221-244.

Naguib, A. N., Tobias, J. D., Hall, M. W., Cismowski, M. J., Miao, Y., Barry, N., Preston, T., Galantowicz, M., \& Hoffman, T. M. (2013). The role of different anesthetic techniques in altering the stress response during cardiac surgery in children: A prospective, double-blinded, and randomized study. Pediatric Critical Care Medicine, 14(5), 481-490.

Palmieri, T. L., Lerine, S., Schonffeld-Warden, N., O’Mara, M. S., \& Greenhalgh, D. G. (2006). Hypothalamic-pituitary-adrenal axis response to sustained stress after major burn injury in children. Journal of Burn Care and Research, 27, 742-748.

Paola, A., Carlo, L., Cinzia, D. R., Valter, P., Pierluigi, N., \& Sollazzi, L. (2015). Stress response to surgery, anesthetics role and impact on cognition. Journal of Anesthesia and Clinical Research, 6(7), 1-5.

Pierce, C. A., \& Voss, B. (2010). Efficacy and safety of ibuprofen and acetaminophen in children and adults: a meta-analysis and qualitative review. Annals of Pharmacotherapy, 44, 489-506.

Russell, P., von Ungern-Sternberg, B. S., \& Schug, S. A. (2013). Perioperative analgesia in pediatric surgery. Current Opinion in Anaesthesiology, 26(4), 420-427.

Sakai, T., O’Flaherty, D., Giesecke, A. H., Kudo, A., Hirota, K., \& Matsuki, A. (1995). Effects of total intravenous anesthesia with propofol on immuno-endocrine changes during surgical stress. Journal of Anesthesia, 9(3), 214-219.

Schnelle, A., Volk, G. F., Finkensieper, M., Meissner, W., \& Guntinas-Lichius, O. (2013). Postoperative pain assessment after pediatric otolaryngologic surgery. Pain Medicine, 14(11), 1786-1796.

Schultz-Machata, A. M., Weiss, M., \& Becke, K. (2014). What's new in pediatric acute pain therapy? Current Opinion in Anaesthesiology, 27(3), 316-322.

Sekhon, V., Menon, P., Arora, S., \& Rao, K. L. (2013). Nephrectomy in children: Comparison of stress response to laparoscopic and open methods. Journal of Indian Association of Pediatric Surgeons, 18(2), 53-57.

Strauss, L. (2012). Anaesthetic management of paediatric adenotonsillectomy. South African Family Practice, 54(3), 17-20.

Tan, T., Bhinder, R., Carey, M., \& Briggs, L. (2010). Day-surgery patients anesthetized with propofol have less postoperative pain than those anesthetized with sevoflurane. Anesthesia and Analgesia, 111(1), 83-85.

Taylor, L. K., Auchus, R. J., Baskin, L. S., \& Miller, W. L. (2013). Cortisol response to operative stress with anesthesia in healthy children. The Journal of Clinical Endocrinology and Metabolism, 98(9), 3687-3693.

Uysal, H. Y., Takmaz, S. A., Yaman, F., Baltaci, B., \& Başar, H. (2011). The efficacy of intravenous paracetamol versus tramadol for postoperative analgesia after adenotonsillectomy in children. Journal of Clinical Anesthesia, 23(1), 53-57.

Vons, K. M., Bijker, J. B., Verwijs, E. W., Majoor, M. H., \& de Graaff, J. C. (2014). Postoperative pain during the first week after adenoidectomy and guillotine adenotonsillectomy in children. Paediatric Anaesthesia, 24(5), 476-482.

Wang, X., Jiang, T., \& Zhao, B. (2014). Effects of different maintain doses of dexmedetomidine on plasma cortisol and glucose during anesthesia recovery period in patients undergoing uvulopalatopharyngoplasty under sevoflurane inhalation anesthesia. Lin Chung Er Bi Yan Hou Tou Jing Wai Ke Za Zhi, 28(15), 1154-1157.

Wolf, A. R. (2012). Effects of regional analgesia on stress responses to pediatric surgery. Paediatric Anaesthesia, 22(1), 19-24.

Yang, L. Q., Li, J. J., Chen, S. Q., \& Wang, Y. W. (2013). Effect of different depths of anesthesia on perioperative stress response in children undergoing adenoidectomy and tonsillectomy. CNS Neuroscience and Therapeutics, 19(2), 134-135.

Yusupov, A. S., Agzamhodjaev, T. S., Fayziev, O. Y., Mamatkulov, I. A., \& Avazov, J. H. (2015). Research of a hormone of stress-cortisol and concentration of blood sugar for an estimation efficiency anesthesia. Austrian Journal of Technical and Natural Sciences, 3(4), 29-31. 